\title{
Accounting Faculty Utilization Of Web-Based Resources To Enhance In-Class Instruction
}

Thomas G. Black, San Jose State University, USA

Howard F. Turetsky, San Jose State University, USA

\begin{abstract}
Our study examines the extent to which accounting faculty use web-based resources to augment classroom instruction. Moreover, we explore the effects of the institutional factors of accounting accreditation and the existence of an accounting Ph.D. program on internet use by accounting academics toward enhancing pedagogy, while controlling for the individual factors of academic rank and gender. We find strong statistical inferences that accounting accreditation signifies an increase in the likelihood that accounting faculty utilize the internet to supplement pedagogy. The presence of an accounting doctoral program, as well as the interactions of accreditation with the ranks of assistant and full professors, in addition to the female gender, are associated with an increase in the odds that faculty integrate the internet in their courses.
\end{abstract}

Keywords: Accounting pedagogy, Internet utilization, accounting academic accreditation

\section{INTRODUCTION}

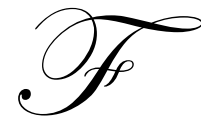

rom its origin in the 1970's as a rudimentary email system, the World Wide Web (the "internet") has grown from a technological novelty to a valuable resource. Email is now the predominant means of communication and the internet, while serving our recreational needs, is a perpetual marketing tool and indispensable management/research instrument utilized in almost all business pursuits. It is difficult to envision a world without internet and hard to imagine awakening without email traffic.

The accounting profession, in particular, has been very proactive in harnessing the power of the internet. Professional accounting organizations, such as the Institute of Management Accountants (IMA) and the Institute of Internal Auditors (IIA), as well as state boards of accountancy, have developed extensive websites that provide their membership access to a wide range of products and services, including web-based continuing education courses. Most recently, the American Institute of Certified Public Accountants (AICPA) has transformed the Uniform CPA Exam from a semi-annual pencil-and-paper exam to a year-round computer-based test. The computer-based delivery facilitates critical skills testing via case study simulations, which require the candidate to utilize the internet to access germane research tools and authoritative literature.

Likewise, it is implicitly presumed that the academic communities, especially at the university level (the "breeding ground" for the embryonic professional), have embraced the internet as a critical pedagogical tool. With few exceptions, American colleges and universities have invested heavily to upgrade their computer systems, local area networks, and internet links. Academics from a diverse array of disciplines have utilized the internet in various modes as an instructional tool to enhance their students' in-class learning and overall educational experience.

The broad-spectrum of our study is to examine whether the premise of web-based resource utilization holds true for the accounting discipline within academe. Given the copious utilization by the accounting profession, it is expected that instruction within the accounting classroom environment relies heavily on the internet (web-based resources). It is anticipated that accounting, similar to other academic disciplines, advances its pedagogy via webbased enhancements that include course syllabi, lecture notes, PowerPoint slides, assignments/quizzes/exams, and assignment/quiz/exam solutions, as well as links to related web sites, cases, research methods, and additional 
reading materials. Generally, this is accomplished by individual faculty members through the design of personal home pages. Incrementally, faculty members could utilize learning management systems courseware, such as WebCT or Blackboard. Another, but far less common application of the Internet, is the development of entire webbased courses, even encompassing entire degree programs.

While the utility of the internet to enhance the learning experience has been embraced in many academic quarters, there is scant empirical evidence that indicates whether or not accounting faculty have followed suit. Consequently, our study examines the extent to which accounting faculty use web-based resources to augment classroom instruction. Moreover, we explore the effects of two institutional and two individual factors upon accounting faculty use of web-based resources to enhance face-to-face instructional activities.

To document the extent to which accounting faculty have embraced the internet to enhance in-class instruction, we examine the internet use of 3,753 tenured and tenure-track faculty members at 413 accounting programs, within business colleges accredited by the Association to Advance Collegiate Schools of Business (AACSB). We employ logistic regression to analyze the influence of the institutional factors of accounting accreditation and the existence of an accounting Ph.D. program on internet use by accounting academics toward enhancing pedagogy. Incrementally, our logistic model analyzes (controls for) academic rank and gender (individual factors).

Our findings indicate that a relatively insignificant number of accounting faculty take advantage of the power of the internet to enhance their classroom activities. Less than sixteen percent of accounting faculty use the internet as an instructional resource. For this internet "usage" group, the results indicate a greater likelihood of affiliation with an institution that has a separately accredited accounting program. Additionally, we find that the presence of an accounting doctoral program, as well as the interactions of accreditation with the ranks of assistant and full professors, in addition to the female gender, are associated with an increase in the odds that faculty integrate the internet in their courses.

The remainder of the paper is organized as follows. Pertinent background information from previous research, to help motivate our research questions, is in the next section. Following that, we describe the research design specifically reviewing the data collection and model we utilize to test our research questions. In the following sections, we present the results, discuss our findings, and draw conclusions.

\section{BACKGROUND}

While the World Wide Web has evolved into a valuable resource that enhances the learning experience, there is relatively little empirical research to indicate whether academe has actually embraced the internet. In a survey of 106 faculty members of the Decision Sciences Institute who identified operations research/management science (OR/MS) as their primary, secondary, or tertiary academic interest areas, Gagnon and Krovi [2000] reported that only 27 percent of faculty teaching introductory OR/MS courses used the internet as part of their course pedagogy. Additionally, the faculty used, on average, three types of internet applications per course. The most frequently assigned purpose was to gather data about a company. Other uses included searching the internet for information/data, downloading syllabi/homework problems, checking homework solutions, accessing articles/cases, reviewing a plant tour, and taking an exam. Gagno and Krovi acknowledge that their results may be somewhat biased in that the likely respondents to their survey are those faculty who do incorporate the internet as part of their teaching pedagogy; consequently, the reported 27 percent of faculty using the internet is very likely overstated.

In a national survey of faculty at engineering schools, accredited by the Accreditation Board for Engineering and Technology, St. Clair and Baker [2003] examined faculty use of course management tools, such as WebCT. Seventy-nine percent of the 369 faculty members surveyed indicated that they had used the internet in their courses. Yet they found that most of the faculty who used the internet did so to perform simple tasks; ninety-six percent indicated they used the internet to e-mail students, eighty-nine percent to link syllabi, seventy-five percent to assign homework, sixty-six percent to post notes, and seventy-six percent to link external websites. Far fewer indicated internet usage for the more complex tasks of homework submission (42\%), administering quizzes (17\%), administering exams (12\%), and automated grading (10\%). 
Starting in Fall 1998 and continuing for five consecutive academic years, 704 faculty members (49\% of total faculty) at Northern Michigan University participated in a study on faculty adoption of internet integration into courses [Poindexter, 2004]. For academic year 1998-99 only 38 percent of the faculty surveyed reported they were internet instructional users. By academic year 2002-03, the last year of the study, nearly 86 percent of the faculty surveyed reported they were internet instructional users. The activity breakdown for faculty using internet instructional tools in academic year 2002-03 was as follows: e-mail communications with students (89\%); online posting of syllabi (85\%), links to websites (76\%); "distribution" of handouts and assignment pages (78\%); "collection" and "return" of assignments (76\%); requiring Web resources for research projects $(68 \%)$; posting lecture notes (52\%); grade notification (51\%); practice tests (34\%); exam "administration" (25\%); online-only courses (21\%); and posting exercises with submission form (8\%).

To examine the use of the Blackboard Learning System (BLS), as a supplement to face-to-face instruction, 862 faculty members at 38 colleges and universities were administered an on-line survey [Woods et al., 2004]. The researchers found that BLS was used by faculty primarily to make course documents available to students and to manage course grades. Eighty-six percent of those surveyed indicated that they frequently or occasionally linked their syllabi, eighty-one percent frequently or occasionally sent e-mails to students, seventy-five percent frequently or occasionally made supplemental readings available, and fifty-nine percent used an on-line grade book. Few faculty used the BLS for instructional or assessment purposes. Forty-four percent of those surveyed indicated they used it to collect assignments, forty-one percent to administer quizzes, thirty-two percent to return assignments, and twenty-five percent that utilized BLS to administer exams.

More recently, in a nationwide on-line survey of 2,316 faculty members from a variety of disciplines, Jones and Johnson-Yale [2005] found that 98 percent of the professors used e-mail as their primary means to communicate with students. The most common purpose for the electronic message was to inquire about or discuss a grade, absence notification, clarification of an assignment, or to schedule an appointment. Fifty-five percent of the professors indicated they utilized course Web sites or Web boards (such as Blackboard) to communicate with their students. The study also found that sixteen percent of those surveyed were teaching an online-only course.

Preceding research targeted at addressing internet utilization by accounting faculty is particularly scant. Baker and White [2000] sent a survey to the chairs of 714 accounting programs, domiciled in the United States, to evaluate the frequency of internet use. Faculty members were requested to indicate the course in which the internet was used and to specify how it was employed in course-related activities. Forty-two percent of the respondents claimed the internet was used to supplement in-class instruction. The most common supplements reported were course syllabus, homework assignments, class notes, and problems solutions. Less frequent uses of the internet included links to professional accounting organizations, on-line quizzes, and web-based access to course-related spreadsheets, databases, and PowerPoint slides.

Further, Peek and Roxas [2002] analyzed the content of the home pages for accounting programs that received separate accounting accreditation from the AACSB. They documented that $93 \%$ of the programs had a standardized faculty listing, where the typical listing included the faculty member's name, photograph, rank, phone number, degree, office location, e-mail address, and professional certifications. Moreover, $76 \%$ of the programs provided either faculty vitas or short biographies. Nonetheless, merely $25 \%$ of the faculty had links to personal home pages.

Given the dearth of research addressing the extent to which academe utilizes web-based resources to enhance pedagogy, we empirically document the extent to which accounting faculty utilize the internet to support face-to-face instruction. Our study is especially relevant in that empirical studies directed at internet usage within the accounting curriculum are virtually nonexistent. Moreover, seeing as the accounting profession is steadfast in its use/adoption of web-based resources, it is a reasonable extension to examine whether academia, the breeding ground for the profession, is likewise resolved to embrace the internet as a critical pedagogical tool. Furthermore, we incrementally contribute to the literature by exploring the effects of institutional and individual factors upon accounting faculty internet usage. 


\section{RESEARCH DESIGN}

\section{(i) Research Question}

We are generally investigating the frequency with which accounting faculty, at AACSB accredited business colleges, integrate web-based resources in their courses. Incrementally, we are also questioning the extent to which institutional and individual factors influence the internet assimilation. Specifically, we explore whether the added distinction of accounting accreditation and/or the existence of an accounting Ph.D. program (institutional factors) affect the internet integration by accounting academics. Moreover, our models analyze (control for) academic rank and gender (individual factors).

\section{(ii) Data Collection}

To examine our research questions, we initially looked at the AACSB website to identify 413 U.S. accounting programs within AACSB accredited colleges of business. According to this listing, we proceeded to the accounting department homepages (or college of business webpage when departments have been "consolidated") to gather data on individual faculty members. After eliminating adjunct and clinical faculty as well as lecturers, we identified 3,753 tenured and tenure-track accounting faculty members for inclusion in the sample. We believe excluding lecturers and adjuncts yields a homogeneous sample of tenure/tenure-track faculty whose full-time vocation is academe.

For each faculty member included in our sample, we attach an institutional categorical variable stipulating whether the affiliated college of business carries separate accounting accreditation. This data is collected from the AACSB website and is accordingly coded "0" for business-only accreditation and "1" for accounting accreditation. Further, we looked at the college and department webpage's to determine if there is a Ph.D. program within the business college and whether accounting is identified as a distinct concentration. Correspondingly, this second institutional categorical variable (linked to each faculty member) is coded " 0 " to indicate the absence of an accounting doctoral program and " 1 " for the existence of a Ph.D. program with an accounting concentration. Note that of the 413 accounting programs within AACSB accredited colleges of business in the U.S., we find 163 to hold separate accounting certification compared with the 250 carrying business-only accreditation. Additionally, there are 89 institutions granting a Ph.D. with an accounting concentration, in contrast to the 324 colleges without an accounting doctoral program.

Moreover, we control for the individual factors of academic rank and gender. The faculty member's rank was obtained from the department or college of business webpage and verified by cross-referencing to either the Hasselback Accounting Faculty Directory 2006-2007 or internet searches via Google. The faculty member's rank is coded " 1 " for assistant professor, "2" for associate professor, and "3" for full professor. Gender is initially coded based on conventional first name association, and then confirmed through Google searches. Consequently, gender is coded " 0 " for male and " 1 " for female.

Concomitant with relating each sampled faculty member with the four independent variables (institutional factors of accounting accreditation and accounting concentration Ph.D.; individual factors of rank and gender), we document the course integration of web-based resources (our dependent variable). By perusing all the personal homepages/information for faculty in our sample (via the linking provided by the accounting program's or the business school's websites), we classify each faculty into one of five types of internet user. The first type of internet user is, in fact, the non-internet user; other than a faculty name listing, we found no evidence of any internet use. The second kind of user had only an e-mail address. The third sort of user generally had an e-mail address, as well as a biographical presentation; this information ranged from just a list of degrees and certifications to extensive curriculum vitae complete with a photograph. The fourth form of usage included faculty who made available (via the internet) supporting course materials to their students. Supporting materials included syllabi, lecture notes, PowerPoint slides, as well as various assignments such as problems, cases, quizzes/tests, often followed by the posting of solutions to the assigned material(s); the extent of use ranged from a routine posting of course syllabi to sophisticated personal homepages. The fifth mode of internet use included faculty who used learning management systems courseware such as WebCT or Blackboard. It is noteworthy that previous research has shown that non- 
accounting faculty use learning management systems (LMS) courseware as a course management/administration tool, an assessment tool, and a small-group discussion tool [Woods et al., 2004].

Subsequent to classifying each of the 3,753 faculty members into one of five internet user types, we group them into two categorizations based on whether the web-based integration is aimed at enhancing in-class instruction. Obviously, the first three classifications are not incorporating the internet with pedagogical intent. Appropriately, we code faculty members in this grouping with a " 0 " to indicate "non-use". In contrast, the fourth and fifth user modes are, to varying degrees, assimilating the internet to enhance in-class learning. Accordingly, we code these faculty members with a "1" to signify internet "usage". The resultant dichotomous (binary) dependent variable is 0/1, denoting internet non-use/use within our model.

Table 1 in the "descriptive statistics" section of the results describes our sample, as well as reflects our data collection. The complete sample of 3,753 tenured and tenure-track accounting faculty is dichotomously partitioned based on internet usage (the dependent variable). Consequently, each "panel" is sequentially segmented according to the codification of our four independent variables.

\section{(iii) Model}

The structure of our complete model that considers the extent to which accounting faculty, at AACSB accredited business colleges, integrate web-based resources in their courses is specified as the probability function:

$$
\operatorname{Prob}(\text { Internet_Use })=\mathrm{F}\left(\beta_{1} * \text { Accreditation }+\beta_{2} * \text { Doctoral }+\beta_{3} * \text { Rank }+\beta_{4} * \text { Gender }\right)
$$

Where:

Institutional parameters $\rightarrow$

Accreditation $=0$ if business-only accreditation, 1 for accounting accreditation;

Doctoral $=0$ if no accounting doctorate program, 1 for accounting doctorate;

Individual parameters $\rightarrow$

Rank $=1$ if assistant professor, 2 if associate professor, 3 for full professor;

Gender $\quad=0$ if male, 1 for female;

Dependent variable $\rightarrow$

Internet_Use $\quad=1$ if internet usage, 0 for non-use.

(iv) Method

We estimate our model utilizing logistic regression. Logistic analysis is a linear probability technique where the dependent variable is nonmetric. Additionally this method accommodates all types of independent variables, inclusive of our categorical parameters, and does not require the assumption of multivariate normality. Logistic regression provides an alternative and preferred way to fit maximum likelihood models with dichotomous dependent (left-hand-side) variables coded as 0/1 (or, coded as 0 and not-0). Compared with logit estimation, logistic is generally favored because it presents the estimates in terms of odds ratios rather than coefficients (if desired, the underlying coefficients can also be displayed). The odds ratios are calculated $e^{\beta_{j}}$ (i.e. exponential is raised to the power of the coefficient) for each independent variable $z_{j}$. When an independent (i.e. "explanatory") variable has no effect the odds ratio will equal 1.00. If the explanatory variable has a positive association with the likelihood of occurrence of the dependent variable (internet usage), the odds ratio will be greater than 1.00 , and statistically significant. Correspondingly, if the explanatory variable has a negative correlation with the likelihood of internet usage, the odds ratio will be statistically significant and less than 1.00. By subtracting one from the ratio and multiplying by 100 , the reader can interpret the odds ratio as a percentage change in the likelihood of the dependent variable (internet usage) given a one-unit increase in the explanatory covariate; accordingly, positive 
associations are interpreted as percentage increases in the likelihood of internet usage and negative correlations are described as percentage reductions in the odds of internet use.

We estimate the complete model (inclusive of all 3,753 faculty observations) to identify the independent covariates that significantly impact the likelihood of internet usage. Consequently, we probe each within each significant factor to determine "why"; basically, we "explore" within an influential "thread". For example, if accounting accreditation is a significant factor in the likelihood of internet usage, then we utilize subsets of logistic regressions to examine whether it is additionally affected by (i.e. interacted by) the presence of an accounting doctoral program as well as the rank and/or gender of the faculty member.

\section{RESULTS}

\section{(i) Descriptive Statistics - Frequency Distributions}

Table 1 describes our sample of 3,753 tenured and tenure-track accounting faculty members. The two panels represent a dichotomous partition corresponding to internet usage (our dependent variable). Accordingly, each panel is sequentially segmented based on the codification of our four independent variables, starting with the institutional factors of accounting accreditation and accounting concentration Ph.D., followed in succession by the individual factors of rank and gender.

As noted in Panel A, there are 585 faculty members (representing 15.6\%) who used the internet to integrate web-based resources in their courses; in contrast (per Panel B) there are 3,168 (84.4\%) who did not use web-based resources to supplement their pedagogy. Total frequency counts for each of our independent variables can be derived by aggregating the totals for each category (variable) across the two panels. For example, the faculty affiliated with an accounting accredited college of business total 1,963 (i.e. 364 from the internet usage group + 1,599 from the non-use group), whereas 1,790 are affiliated with a business-only accredited college of business (i.e. 221 from the internet usage group $+1,569$ from the non-use group). Likewise, there are 1,147 (i.e. $29+150+316+$ 652) accounting faculty affiliated with an institution granting a Ph.D. with an accounting concentration, with 802 (i.e. $150+652$ ) being affiliated with both an accounting accredited and accounting Ph.D. granting institution. Similar totals can be calculated for the individual factors of academic rank and gender.

Incremental to the number counts, frequency percentages are documented for each sublevel within the dependent variable panel(s). The noted percentages can then be multiplied to compute the percent that an individual subgroup connotes of a "higher" group, dependent variable partition, or complete sample. For example, within the internet usage partition, male assistant professors affiliated with both an accounting Ph.D. granting and accounting accredited institution comprise just over $3 \%$ (i.e. $.486 \times .247 \times .412 \times .622$ ) of the faculty who incorporate the internet in their pedagogy. Note that the same percentages can be calculated by simply dividing the frequency count by the total count for the specified group (i.e. $3 \%=18 / 585$ ).

While statistically significant inferences cannot be drawn from descriptive data, the frequency distributions do offer some propositions regarding internet usage. Overall, a rather low percentage $(15.6 \%=585 / 3,753)$ of "total" faculty appear to be using web-based resources to enhance classroom instruction. However, the percentages tend to signify that accounting accreditation is a key differentiator of internet usage versus non-use; $62.2 \%$ of the faculty who use the internet as a pedagogical tool are affiliated with an accounting accredited university $37.8 \%$ are affiliated with a business-only accredited university), while only $50.5 \%$ of faculty not employing the internet are at an institution that is accounting accredited (with $49.5 \%$ at a business-only institution). Likewise, a greater percentage of faculty affiliated with accounting accredited programs use the Internet $(18.5 \%=364 / 1,963)$ than faculty affiliated with business-only accredited programs $(12.3 \%=221 / 1,790)$.

Based solely on the descriptive data, there is an indication that the accounting accreditation program affiliation will be a significant factor in differentiating between who utilizes the internet and those that do not. The regression analyses that follow will draw the statistically significant inferences. 
Table 1. Descriptive Statistics - Frequency Distributions

\begin{tabular}{|c|c|c|c|c|c|c|c|c|c|c|c|c|c|c|c|c|c|c|c|c|c|c|c|}
\hline \multicolumn{24}{|c|}{$\begin{array}{l}\text { Internet Usage } \\
585\end{array}$} \\
\hline \multicolumn{12}{|c|}{$\begin{array}{c}\text { Business-only Accreditation } \\
221 \\
37.8 \% \\
\end{array}$} & \multicolumn{12}{|c|}{$\begin{array}{c}\text { Accounting Accreditation } \\
364 \\
62.2 \% \\
\end{array}$} \\
\hline \multicolumn{6}{|c|}{$\begin{array}{c}\text { Non-Doctorate } \\
192 \\
86.9 \%\end{array}$} & \multicolumn{6}{|c|}{$\begin{array}{c}\text { Doctorate } \\
29 \\
13.1 \%\end{array}$} & \multicolumn{6}{|c|}{$\begin{array}{c}\text { Non-Doctorate } \\
214 \\
58.8 \%\end{array}$} & \multicolumn{6}{|c|}{$\begin{array}{c}\text { Doctorate } \\
150 \\
41.2 \%\end{array}$} \\
\hline \multicolumn{2}{|c|}{$\begin{array}{c}\text { Asst } \\
42 \\
21.9 \%\end{array}$} & \multicolumn{2}{|c|}{$\begin{array}{c}\text { Assoc } \\
62 \\
32.3 \%\end{array}$} & \multicolumn{2}{|c|}{$\begin{array}{c}\text { Full } \\
88 \\
45.8 \%\end{array}$} & \multicolumn{2}{|c|}{$\begin{array}{c}\text { Asst } \\
7 \\
24.2 \%\end{array}$} & \multicolumn{2}{|c|}{$\begin{array}{c}\text { Assoc } \\
9 \\
31.0 \%\end{array}$} & \multicolumn{2}{|c|}{$\begin{array}{c}\text { Full } \\
13 \\
44.8 \%\end{array}$} & \multicolumn{2}{|c|}{$\begin{array}{c}\text { Asst } \\
62 \\
29.0 \%\end{array}$} & \multicolumn{2}{|c|}{$\begin{array}{c}\text { Assoc } \\
77 \\
36.0 \%\end{array}$} & \multicolumn{2}{|c|}{$\begin{array}{c}\text { Full } \\
75 \\
35.0 \%\end{array}$} & \multicolumn{2}{|c|}{$\begin{array}{c}\text { Asst } \\
37 \\
24.7 \%\end{array}$} & \multicolumn{2}{|c|}{$\begin{array}{c}\text { Assoc } \\
43 \\
28.7 \%\end{array}$} & \multicolumn{2}{|c|}{$\begin{array}{l}\text { Full } \\
70 \\
46.6 \%\end{array}$} \\
\hline $\mathrm{M}$ & $\mathrm{F}$ & $\mathrm{M}$ & $\mathrm{F}$ & $\mathrm{M}$ & $\mathrm{F}$ & M & $\mathrm{F}$ & $\mathrm{M}$ & $\mathrm{F}$ & $\mathrm{M}$ & $\mathrm{F}$ & $\mathrm{M}$ & $\mathrm{F}$ & $\mathrm{M}$ & $\mathrm{F}$ & $\mathrm{M}$ & $\mathrm{F}$ & M & $\mathrm{F}$ & M & $\mathrm{F}$ & M & $\mathrm{F}$ \\
\hline 25 & 17 & 45 & 17 & 71 & 17 & 5 & 2 & 8 & 1 & 12 & 1 & 33 & 29 & 52 & 25 & 67 & 8 & 18 & 19 & 31 & 12 & 66 & 4 \\
\hline $59.5 \%$ & $40.5 \%$ & $72.6 \%$ & $27.4 \%$ & $80.7 \%$ & $19.3 \%$ & $71.4 \%$ & $28.6 \%$ & $88.9 \%$ & $11.1 \%$ & $92.3 \%$ & $7.7 \%$ & $53.2 \%$ & $46.8 \%$ & $67.5 \%$ & $32.5 \%$ & $89.3 \%$ & $10.7 \%$ & $48.6 \%$ & $51.4 \%$ & $72.1 \%$ & $27.9 \%$ & $94.3 \%$ & $5.7 \%$ \\
\hline
\end{tabular}

Panel A.

\begin{tabular}{|c|c|c|c|c|c|c|c|c|c|c|c|c|c|c|c|c|c|c|c|c|c|c|c|}
\hline \multicolumn{24}{|c|}{$\begin{array}{c}\text { Non-Use } \\
3,168\end{array}$} \\
\hline \multicolumn{12}{|c|}{$\begin{array}{c}\text { Business-only Accreditation } \\
1,569 \\
49.5 \%\end{array}$} & \multicolumn{12}{|c|}{$\begin{array}{c}\text { Accounting Accreditation } \\
1,599 \\
505 \%\end{array}$} \\
\hline \multicolumn{6}{|c|}{$\begin{array}{c}\text { Non-Doctorate } \\
1,253 \\
79.9 \%\end{array}$} & \multicolumn{6}{|c|}{$\begin{array}{c}\text { Doctorate } \\
316 \\
20.1 \%\end{array}$} & \multicolumn{6}{|c|}{$\begin{array}{c}\text { Non-Doctorate } \\
947 \\
59.2 \% \\
\end{array}$} & \multicolumn{6}{|c|}{$\begin{array}{c}\text { Doctorate } \\
652 \\
40.8 \%\end{array}$} \\
\hline \multicolumn{2}{|c|}{$\begin{array}{c}\text { Asst } \\
302 \\
24.1 \%\end{array}$} & \multicolumn{2}{|c|}{$\begin{array}{c}\text { Assoc } \\
460 \\
36.7 \%\end{array}$} & \multicolumn{2}{|c|}{$\begin{array}{c}\text { Full } \\
491 \\
39.2 \%\end{array}$} & \multicolumn{2}{|c|}{$\begin{array}{c}\text { Asst } \\
108 \\
34.2 \%\end{array}$} & \multicolumn{2}{|c|}{$\begin{array}{c}\text { Assoc } \\
79 \\
25.0 \%\end{array}$} & \multicolumn{2}{|c|}{$\begin{array}{c}\text { Full } \\
129 \\
40.8 \%\end{array}$} & \multicolumn{2}{|c|}{$\begin{array}{c}\text { Asst } \\
215 \\
22.7 \%\end{array}$} & \multicolumn{2}{|c|}{$\begin{array}{c}\text { Assoc } \\
357 \\
37.7 \%\end{array}$} & \multicolumn{2}{|c|}{$\begin{array}{c}\text { Full } \\
375 \\
39.6 \%\end{array}$} & \multicolumn{2}{|c|}{$\begin{array}{c}\text { Asst } \\
153 \\
23.5 \%\end{array}$} & \multicolumn{2}{|c|}{$\begin{array}{c}\text { Assoc } \\
211 \\
32.3 \%\end{array}$} & \multicolumn{2}{|c|}{$\begin{array}{c}\text { Full } \\
288 \\
44.2 \%\end{array}$} \\
\hline $\mathrm{M}$ & $\mathrm{F}$ & $M$ & $\mathrm{~F}$ & $\mathrm{M}$ & $\mathrm{F}$ & $\mathrm{M}$ & $F$ & $\mathrm{M}$ & $F$ & $\mathrm{M}$ & $\mathrm{F}$ & $\mathrm{M}$ & $F$ & $\mathrm{M}$ & $\mathrm{F}$ & $\mathrm{M}$ & $\mathrm{F}$ & $M$ & $F$ & $\mathrm{M}$ & $\mathrm{F}$ & $\mathrm{M}$ & $F$ \\
\hline $\begin{array}{c}165 \\
546 \%\end{array}$ & $\begin{array}{c}137 \\
454 \%\end{array}$ & $\begin{array}{r}325 \\
707 \%\end{array}$ & $\begin{array}{c}135 \\
293 \%\end{array}$ & $\begin{array}{c}386 \\
786 \%\end{array}$ & $\begin{array}{l}105 \\
214 \%\end{array}$ & $\begin{array}{c}72 \\
667 \%\end{array}$ & 36 & $\begin{array}{c}61 \\
772 \%\end{array}$ & $\begin{array}{c}18 \\
228 \%\end{array}$ & $\begin{array}{c}117 \\
907 \%\end{array}$ & $\begin{array}{c}12 \\
93 \%\end{array}$ & $\begin{array}{c}142 \\
66.0 \%\end{array}$ & $\begin{array}{c}73 \\
34.0 \%\end{array}$ & $\begin{array}{c}262 \\
73.4 \%\end{array}$ & $\begin{array}{c}95 \\
26.6 \%\end{array}$ & $\begin{array}{c}317 \\
84.5 \%\end{array}$ & $\begin{array}{c}58 \\
15.5 \%\end{array}$ & $\begin{array}{c}99 \\
64.7 \%\end{array}$ & $\begin{array}{c}54 \\
35.3 \%\end{array}$ & $\begin{array}{c}149 \\
70.6 \%\end{array}$ & $\begin{array}{c}62 \\
29.4 \%\end{array}$ & $\begin{array}{c}247 \\
85.8 \%\end{array}$ & $\begin{array}{c}41 \\
14.2 \%\end{array}$ \\
\hline
\end{tabular}

Panel B. 


\section{(ii) Multivariate and Univariate Analyses}

We utilize logistic regression to estimate our multivariate model, for the complete sample of 3,753 tenured and tenure-track accounting faculty:

$$
\text { Prob }(\text { Internet_Use })=\mathrm{F}\left(\beta_{1} * \text { Accreditation }+\beta_{2} * \text { Doctoral }+\beta_{3} * \text { Rank }+\beta_{4} * \text { Gender }\right)
$$

We present the results in Table 2 (Panel A). The model is significant (Chi-Square $=29.170$, significant at 0.000 ) as an estimator of the extent to which accounting faculty integrate web-based resources in their courses. More specifically, accreditation has a highly significant positive association with faculty internet usage to supplement their pedagogy. An odds ratio of 1.659 (p-value .000) indicates that accounting accreditation (relative to business-only) increases the likelihood by $65.9 \%$ that accounting faculty use web-based resources to augment classroom instruction. The presence of an accounting doctorate program, the rank, or gender of the professor is not significant in the multivariate model exhibited in Panel A of Table 2.

Further, on the complete sample of 3,753 tenured and tenure-track accounting faculty, we estimate univariate models for each of the institutional and individual parameters (see Table 2, Panel B). Consistent with our multivariate results, only the institutional variable of accreditation is significant on a univariate basis. The odds that faculty integrate the internet in their courses is increased by $61.6 \%$ (p-value .000 ) when the affiliated college of business carries separate accounting accreditation.

Table 2: Multivariate and Univariate Regressions

Panel A - multivariate model

Model: Prob(Internet_Use $)=\mathrm{F}\left(\beta_{1} *\right.$ Accreditation $+\beta_{2} *$ Doctoral $+\beta_{3} *$ Rank $+\beta_{4} *$ Gender $)$

$\{$ LR Chi-Square $=\mathbf{2 9 . 1 7 0}$

Prob $\left.>\mathrm{Chi}^{2}=\mathbf{0 . 0 0 0}\right\}$

\begin{tabular}{|c|c|c|c|c|}
\hline Covariate $\downarrow$ & Odds Ratio & Beta Coefficient & z-statistic & $\mathrm{P}>\mathrm{z}$ \\
\hline Accreditation & 1.659 & 0.506 & 5.339 & 0.000 \\
\hline Doctoral & 0.885 & -0.122 & -1.216 & 0.224 \\
\hline Rank & 1.011 & 0.010 & 0.179 & 0.858 \\
\hline Gender & 1.016 & 0.016 & 0.149 & 0.881 \\
\hline Sample Size & 3,753 & & & \\
\hline
\end{tabular}

Note: Bold indicates significance at $\alpha \leq .01$

\section{Panel B - univariate models}

\begin{tabular}{|c|c|c|c|c|}
\hline Covariate $\rightarrow$ & Accreditation & Doctoral & Rank & Gender \\
\hline Odds Ratio & 1.616 & 1.002 & 1.013 & 0.995 \\
\hline Beta Coefficient & 0.480 & 0.002 & 0.013 & -0.005 \\
\hline z-statistic & 5.196 & 0.021 & 0.227 & -0.046 \\
\hline$P>|z|$ & 0.000 & 0.984 & 0.820 & 0.964 \\
\hline LR Chi-Square & 27.620 & 0.000 & 0.050 & 0.000 \\
\hline Prob $>\mathrm{Chi}^{2}$ & 0.000 & 0.984 & 0.820 & 0.964 \\
\hline Sample Size & 3,753 & 3,753 & 3,753 & 3,753 \\
\hline
\end{tabular}

Note: Bold indicates significance at $\alpha \leq .01$ 
Table 3: Interactions/Restrictions of Accreditation Model

\section{Panel A - Accreditation Interactions}

Panel A of Table 3 presents the regression results for the interactions of Accreditation (A) with the other three covariates, Doctoral (D), Rank (R), and Gender (G). Note further that Rank is "tabulated" so that variables for the three levels are generated: for Assistant Professor $\left(\mathrm{R}_{1}\right)$, all assistant professors are coded 1 and associate and full coded 0; for Associate Professor $\left(\mathrm{R}_{2}\right)$, all associate professors are coded 1 and the other two levels coded 0 ; and for Full Professor $\left(\mathrm{R}_{3}\right)$, all full professors are coded 1 and the other two levels coded 0 . For all regressions in Panel A, the sample is the complete one of 3,753 faculty members.

\begin{tabular}{|c|c|c|c|c|c|c|c|c|c|c|c|c|c|c|c|}
\hline Interaction $\rightarrow$ & $\mathrm{AD}$ & $\mathrm{AR}_{1}$ & $\mathrm{AR}_{2}$ & $\mathrm{AR}_{3}$ & $\mathrm{AG}$ & $\mathrm{ADR}_{1}$ & $\mathrm{ADR}_{2}$ & $\mathrm{ADR}_{3}$ & ADG & $\mathrm{AR}_{1} \mathrm{G}$ & $\mathrm{AR}_{2} \mathrm{G}$ & $\mathrm{AR}_{3} \mathrm{G}$ & $\mathrm{ADR}_{1} \mathrm{G}$ & $\mathrm{ADR}_{2} \mathrm{G}$ & $\mathrm{ADR}_{3} \mathrm{G}$ \\
\hline Odds Ratio & 1.331 & 1.550 & 1.181 & 1.245 & 1.445 & 1.331 & 1.112 & 1.359 & 1.220 & 2.140 & 1.295 & 0.649 & 1.936 & 1.049 & 0.525 \\
\hline Beta Coefficient & 0.286 & 0.438 & 0.167 & 0.219 & 0.368 & 0.286 & 0.106 & 0.307 & 0.199 & 0.761 & 0.258 & -0.432 & 0.661 & 0.048 & -0.644 \\
\hline z-statistic & 2.737 & 3.550 & 1.482 & 2.083 & 2.975 & 1.511 & 0.610 & 2.168 & 1.034 & 4.329 & 1.371 & -1.398 & 2.441 & 0.151 & -1.225 \\
\hline$P>|z|$ & 0.006 & 0.000 & 0.138 & 0.037 & 0.003 & 0.131 & 0.542 & 0.030 & 0.301 & 0.000 & 0.171 & 0.162 & 0.015 & 0.880 & 0.220 \\
\hline LR Chi-Square & 7.260 & 11.860 & 2.150 & 4.230 & 8.400 & 2.170 & 0.360 & 4.470 & 1.030 & 16.780 & 1.790 & 2.180 & 5.340 & 0.020 & 1.790 \\
\hline Prob $>\mathrm{Chi}^{2}$ & 0.007 & 0.001 & 0.143 & 0.040 & 0.004 & 0.141 & 0.546 & 0.035 & 0.310 & 0.000 & 0.181 & 0.140 & 0.021 & 0.881 & 0.181 \\
\hline Sample Size & 3,753 & 3,753 & 3,753 & 3,753 & 3,753 & 3,753 & 3,753 & 3,753 & 3,753 & 3,753 & 3,753 & 3,753 & 3,753 & 3,753 & 3,753 \\
\hline
\end{tabular}

[Note: All the "other" interactions of the independent covariates, not including Accreditation, show no significance.]

\section{Panel B - Accreditation “univariate” with restrictions}

Panel B of Table 3 "restricts" the sample(s) to simulate the Interactions of Accreditation with the other three independent covariates (Doctoral, Rank, \& Gender). For example, we test the significance of Accreditation for the sub-sample of faculty members affiliated with a university having an accounting doctorate program and alternatively for the sample restricted to universities without an accounting doctorate program; combined, these two subgroups tend to "simulate" the interaction AD.

\begin{tabular}{|c|c|c|c|c|c|c|c|}
\hline Restriction $\rightarrow$ & Doctorate & Non-Doctorate & Assistant & Associate & Full & Male & Female \\
\hline Odds Ratio & 2.507 & 1.475 & 2.251 & 1.604 & 1.343 & 1.489 & 2.040 \\
\hline Beta Coefficient & 0.919 & 0.388 & 0.811 & 0.472 & 0.295 & 0.398 & 0.713 \\
\hline z-statistic & 4.292 & 3.586 & 4.296 & 2.928 & 2.087 & 3.718 & 3.903 \\
\hline$P>|z|$ & 0.000 & 0.000 & 0.000 & 0.003 & 0.037 & 0.000 & 0.000 \\
\hline LR Chi-Square & 21.410 & 12.880 & 19.430 & 8.78 & 4.400 & 14.080 & 15.790 \\
\hline Prob $>\mathrm{Chi}^{2}$ & 0.000 & 0.000 & 0.000 & 0.003 & 0.036 & 0.000 & 0.000 \\
\hline Sample Size & 1,147 & 2,606 & 926 & 1,298 & 1,529 & 2,775 & 978 \\
\hline
\end{tabular}

Note: Bold indicates significance at $\alpha \leq .01$

Note: Italic indicates significance at $\alpha \leq .05$ 


\section{(iii) Accreditation Analyzed - Interactions \& Restrictions}

Since the institutional covariate of accreditation specifies a clear significant linkage with the likelihood that faculty utilize the internet to supplement pedagogy, we consequently probe within this influential "thread" to determine "why". Especially, we utilize subsets of logistic regressions to examine whether accounting accreditation is additionally affected by (i.e. interacted by) the presence of an accounting doctoral program as well as the rank and/or gender of the faculty member. We present the results in Table 3.

Panel A specifically considers all of the interactions of "accreditation" (A) with the three other covariates, doctoral (D), rank (R), and gender (G) on the complete sample of 3,753 tenured and tenure-track accounting faculty. Further, rank is "tabulated" so that variables for the three levels of assistant professor $\left(\mathrm{R}_{1}\right)$, associate professor $\left(\mathrm{R}_{2}\right)$, and full professor $\left(\mathrm{R}_{3}\right)$ are generated. When accounting accreditation is coupled with (interacted by) the presence of an accounting doctoral program (i.e. $\mathrm{AD}$ ), the odds that faculty integrate the internet in their courses is increased by $33.1 \%$ (p-value .006). The interaction of accreditation with assistant professors (i.e. $\mathrm{AR}_{1}$ ) and likewise with full professors $\left(\mathrm{AR}_{3}\right)$ enhances the likelihood of internet integration by $55 \%$ (p-value .000) and $24.5 \%$ (p-value .037), respectively; and the interaction of accreditation with females (i.e. AG where $G$ is coded 1 for female) is significantly associated with a $44.5 \%$ (p-value .003) increase in the utilization of the internet as an instructional resource by accounting academics. Significant three-way interactions are $\mathrm{ADR}_{3}$ and $\mathrm{AR}_{1} \mathrm{G}$ inferring, for example, that accounting accreditation interacted jointly with female assistant professors increases the likelihood of internet integration within accounting courses by $114 \%$ (p-value .000). The only significant four-way interaction is $\mathrm{ADR}_{1} \mathrm{G}$ implying that female assistant professors at accounting accredited colleges that house an accounting doctoral program are $93.6 \%$ (p-value .015) more likely to integrate the internet within their pedagogy.

Panel B of Table 3 "restricts" the sample to simulate the interactions of "accreditation" (A), consequently reinforcing the significant interactions demarcated in Panel A. For example, we test the significance of accreditation for the sub-sample of male faculty members and alternatively for the female sub-sample (i.e. gender is being alternately "restricted" to males and females); combined these two subgroups (restrictions) tend to "simulate" the interaction AG.

\section{(iv) Within Accounting Accreditation}

Continuing to analyze the significance of the institutional covariate of accreditation, we estimate regressions within the subgroup of 1,963 of faculty members affiliated with a college of business carrying separate accounting accreditation. Restricting to this sub-sample, Table 4 presents the significant results of our "univariate" tests as well as the significant "interactions" among the three other covariates, doctoral (D), rank (R) where rank is tabulated to depict the three levels, and gender $(\mathrm{G})$. Within the "accounting accreditation" subgroup of faculty members, it is noteworthy that female assistant professors are $76.1 \%$ (p-value .002 ) more likely to integrate the internet in their courses; whereas, for female full professors, the odds of internet use are reduced by $48.3 \%$ (p-value .034). Moreover, for the significant interactions, we restrict the sub-sample further to underscore the inference(s). Accordingly, Table 4 signifies the odds that other "restricted" subgroups, within the "accounting accreditation" group, will integrate web-based resources into pedagogy. For instance, assistant professors, restricted to female professors at colleges of business carrying separate accounting accreditation but without an accounting doctorate program (sample size $=288$ ), are $84.2 \%$ (p-value .036$)$ more likely to integrate the internet in their courses; however, full professors, within the same restricted sample, are $57.1 \%$ (p-value .038) less likely to integrate the internet. 
Table 4: Model(s) of Accounting Accreditation Subgroup

Table 4 presents regression results within the Accounting Accreditation subgroup (i.e. the sub-sample of faculty members affiliated with a college of business carrying separate accounting accreditation). The "univariate" significance as well as the significant "interactions" for the other three covariates, Doctoral (D), Rank (R), and Gender (G) are shown (note that rank is "tabulated" so that variables for the three levels are generated). For the significant interactions, we further "restrict" the sample to test the significance of each covariate within the specified subgroup(s).

\begin{tabular}{|c|c|c|c|c|c|c|}
\hline Covariate & Restriction(s) & $\begin{array}{c}\text { Sample } \\
\text { Size }\end{array}$ & Odds Ratio & $\begin{array}{c}\text { Beta } \\
\text { Coefficient }\end{array}$ & z-statistic & $P>|z|$ \\
\hline Rank1 & & 1,963 & 1.250 & 0.223 & 1.690 & 0.091 \\
\hline $\mathrm{R} 1 \mathrm{G}$ & & 1,963 & 1.761 & 0.566 & 3.135 & 0.002 \\
\hline Rank1 & Female & 480 & 1.975 & 0.680 & 2.955 & 0.003 \\
\hline Rank1 & Male & 1,483 & 0.955 & -0.046 & -0.267 & 0.789 \\
\hline Gender & Assistant & 467 & 1.786 & 0.580 & 2.532 & 0.011 \\
\hline R3G & & 1,963 & 0.517 & -0.661 & -2.122 & 0.034 \\
\hline Rank3 & Female & 480 & 0.405 & -0.904 & -2.741 & 0.006 \\
\hline Rank3 & Male & 1,483 & 1.147 & 0.137 & 1.017 & 0.309 \\
\hline Gender & Full & 808 & 0.514 & -0.666 & -2.076 & 0.038 \\
\hline DR1G & & 1,963 & 1.576 & 0.455 & 1.664 & 0.096 \\
\hline Doctoral & Assistant/Female & 175 & 0.886 & -0.121 & -0.351 & 0.725 \\
\hline Doctoral & Assistant/Male & 292 & 0.782 & -0.245 & -0.765 & 0.444 \\
\hline Rank1 & Doctorate/Female & 192 & 2.265 & 0.818 & 2.159 & 0.031 \\
\hline Rank1 & Doctorate/Male & 610 & 0.742 & -0.298 & -1.064 & 0.287 \\
\hline Rank1 & Non-Doctorate/Female & 288 & 1.842 & 0.611 & 2.095 & 0.036 \\
\hline Rank1 & Non-Doctorate/Male & 873 & 1.131 & 0.123 & 0.564 & 0.573 \\
\hline Gender & Assistant/Doctorate & 190 & 1.935 & 0.660 & 1.785 & 0.074 \\
\hline Gender & Assistant/Non-Doctorate & 277 & 1.709 & 0.536 & 1.833 & 0.067 \\
\hline DR3G & & 1,963 & 0.422 & -0.862 & -1.636 & 0.102 \\
\hline Doctoral & Full/Female & 111 & 0.707 & -0.346 & -0.536 & 0.592 \\
\hline Doctoral & Full/Male & 697 & 1.264 & 0.234 & 1.214 & 0.225 \\
\hline Rank3 & Doctorate/Female & 192 & 0.365 & -1.008 & -1.795 & 0.073 \\
\hline Rank3 & Doctorate/Male & 610 & 1.352 & 0.302 & 1.445 & 0.148 \\
\hline Rank3 & Non-Doctorate/Female & 288 & 0.429 & -0.846 & -2.072 & 0.038 \\
\hline Rank3 & Non-Doctorate/Male & 873 & 1.005 & 0.005 & 0.025 & 0.980 \\
\hline Gender & Full/Doctorate & 358 & 0.365 & -1.008 & -1.859 & 0.063 \\
\hline Gender & Full/Non-Doctorate & 450 & 0.653 & -0.427 & -1.066 & 0.286 \\
\hline
\end{tabular}

Note: Bold indicates significance at $\alpha \leq .05$

Note: Italic indicates significance at $\alpha \leq .10$

\section{(v) Within Business-only Accreditation}

Alternately, in Table 5, we present the regression results within the sub-sample of faculty members affiliated with a college of business carrying business-only (i.e. not separate accounting) accreditation. Of notable significance, within this subgroup of 1,790 of faculty members at colleges without separate accounting accreditation, is that faculty at colleges with an accounting doctorate program are $40.1 \%$ (p-value .014) less likely to integrate web-based resources into pedagogy; especially, assistant professors are $55.8 \%$ (p-value .040) less likely to integrate the internet. When we restrict the sub-sample further, it is noteworthy that faculty at colleges with an accounting doctorate program, restricted to male professors at colleges of business without separate accounting accreditation (sample size $=1,292)$, are $37.9 \%$ (p-value .037) less likely to integrate the internet. 
Table 5. Model(s) of Business-only Accreditation Subgroup

Table 5 presents regression results within the Buiness-only Accreditation subgroup (i.e. the sub-sample of faculty members affiliated with a college of business that does not hold separate accounting accreditation). The "univariate" significance as well as the significant "interactions" for the other three covariates, Doctoral (D), Rank (R), and Gender (G) are shown (note that rank is "tabulated" so that variables for the three levels are generated). For the significant interactions, we further "restrict" the sample to test the significance of each covariate within the specified subgroup(s).

\begin{tabular}{llccccc}
\hline Covariate & Restriction(s) & $\begin{array}{c}\text { Sample } \\
\text { Size }\end{array}$ & Odds Ratio & $\begin{array}{c}\text { Beta } \\
\text { Coefficient }\end{array}$ & z-statistic & $P>|z|$ \\
\hline Doctoral & & 1,790 & $\mathbf{0 . 5 9 9}$ & $\mathbf{- 0 . 5 1 3}$ & -2.454 & 0.014 \\
Rank & & 1,790 & 1.175 & 0.162 & 1.765 & 0.078 \\
Rank3 & & 1,790 & 1.288 & 0.253 & 1.752 & 0.080 \\
DR1 & & 1,790 & $\mathbf{0 . 4 4 2}$ & $\mathbf{- 0 . 8 1 5}$ & -2.055 & 0.040 \\
Doctoral & Assistant & 459 & 0.466 & -0.763 & -1.803 & 0.071 \\
Rank1 & Doctorate & 345 & 0.613 & -0.490 & -1.089 & 0.276 \\
Rank1 & Non-Doctorate & 1,445 & 0.882 & -0.126 & -0.674 & 0.500 \\
DG & & 1,790 & 0.420 & -0.868 & -1.669 & 0.095 \\
Doctoral & Female & 498 & 0.448 & -0.803 & -1.498 & 0.134 \\
Doctoral & Male & 1,292 & $\mathbf{0 . 6 2 1}$ & $\mathbf{- 0 . 4 7 6}$ & -2.083 & 0.037 \\
Gender & Doctorate & 345 & 0.606 & -0.501 & -0.901 & 0.368 \\
Gender & Non-Doctorate & 1,445 & 0.840 & -0.174 & -0.995 & 0.320 \\
\hline
\end{tabular}

Note: Bold indicates significance at $\alpha \leq .05$

Note: Italic indicates significance at $\alpha \leq .10$

\section{CONCLUSIONS AND IMPLICATIONS}

Our study examines whether the premise of web-based resource utilization holds true for the accounting discipline within academe. It is implicitly presumed that academic communities (the "breeding ground" for the embryonic professional) have embraced the internet as a critical pedagogical tool. Whereas the utility of the internet to enhance learning has indubitably been embraced in many academic quarters, there is negligible empirical evidence indicating whether or not accounting faculty have followed suit. Consequently, our study examines the extent to which accounting faculty use web-based resources to augment classroom instruction. Moreover, we explore the effects of the institutional factors of accounting accreditation and the existence of an accounting Ph.D. program on internet use by accounting academics toward enhancing pedagogy, while controlling for the individual factors of academic rank and gender.

While a rather low percentage of "total" accounting faculty are using web-based resources to augment classroom instruction, we do find statistically significant inferences that accounting accreditation is a key differentiator of internet usage versus non-use. Since accounting accreditation signifies an increase in the likelihood that faculty utilize the internet to supplement pedagogy, we probe within this influential "thread" to determine "why". The presence of an accounting doctoral program and the interactions of accreditation with the ranks of assistant and full professors are associated with an increase in the odds that faculty integrate the internet in their courses. Likewise, the interaction of accreditation with females is significantly associated with an increase in the utilization of the internet as an instructional resource by accounting academics. There are further implications that female assistant professors at colleges carrying separate accounting accreditation, along with those that house an accounting doctoral program, are considerably more likely to integrate the internet within their pedagogy. Alternatively, within the sub-sample of faculty members affiliated with a college of business carrying business-only (i.e. not separate accounting) accreditation, the presence of an accounting doctoral program reduces the likelihood that faculty will integrate web-based resources into pedagogy; males, as well as assistant professors, are particularly less likely to integrate the internet.

Considering our findings, we speculate that faculty are unwilling to expend a scarce resource (time) on activities (integrating the internet into the classroom) that have little or no economic/professional payoff, especially given the reward (promotion) system at many colleges being weighted toward the research component. This tends to offer an explanation as to the relative paucity of internet integration by accounting faculty. As for the strong positive significance of separate accounting program accreditation as a determining factor of internet integration, the 
AACSB guidelines for accounting program accreditation provide some elucidation. The AACSB (2005) states that the separate accreditation process is intended to promote high quality innovative accounting education programs where, in considering the quality of accounting programs, such factors as the design and effectiveness of the curriculum and the resources needed and used for educational purposes are critical. Thus, if accounting accredited programs are more innovative (e.g., integrating the internet into the classroom) and have more resources to promote such innovation (e.g., release time and grants) than accounting programs that don't have separate accounting accreditation, we would expect accreditation to have a positive effect on internet use. Moreover, the positive influence of an accounting doctoral program, coupled with separate accreditation, can in all likelihood be attributed to the help given by the doctoral students in enhancing pedagogy via web-based resources. The overall positive association of the rank of assistant professor is seemingly explained by their "newness" to academe, which likely correlates with a greater comfort level in the utilization technology to enhance their pedagogy.

It is notable that this research is exploratory. There are consequently several limitations of this study, which, to strike an optimistic chord, present opportunities to extend this line of research. For instance, we did not categorize faculty according to areas of teaching interest. Research can explore whether different teaching specializations impact internet utilization for pedagogical purposes. For example, faculty teaching AIS (Accounting Information Systems) are no doubt more likely to use the internet for classroom purposes, but what about financial accounting relative to managerial compared with tax? More fundamental to this line of research is the belief that there is a correlation between postings on faculty webpages and the integration of the internet to enhance pedagogy; however, potential disconnects could modify our results. For instance, faculty who integrate the internet, but reside at colleges without a webmaster, were probably not recorded as a "positive" observation during our data collection. Accordingly, future research can utilize survey instruments to further assess accounting faculty utilization of webbased resources to enhance in-class instruction.

\section{AUTHOR INFORMATION}

Dr. Thomas G. Black is a Professor of Accounting at San Jose State University. He holds a Ph.D. in Accounting from the University of Missouri - Columbia. He is also a CPA and CMA. His primary research interest is accounting education. He has published in Management Accounting, CPA Journal, The Bankers Magazine, Journal of Small Business Management, The Journal of Commercial Bank Lenders, The Government Accountant's Journal, New Accountant, and the Journal of Accounting Education.

Dr. Howard F. Turetsky is a Professor of Accounting at San Jose State University. He holds a Ph.D. from Virginia Commonwealth University \& is also a CPA. His research interests include: financial distress; going concern issues; downsizing; mergers and acquisitions; corporate governance; MVA-EVA; and accounting education. He has published in Review of Quantitative Finance and Accounting, Advances in Accounting, Review of Accounting and Finance, Corporate Governance, Mergers \& Acquisitions, Internal Auditing, New Accountant, and Advances in Accounting Education. Additionally, he received the College of Business "outstanding graduate professor" award and is Co-Editor of the Review of Accounting and Finance.

\section{REFERENCES}

1. Baker, Richard and Clinton E. White, Jr. "Internet Uses in Accounting Education: Survey Results," Journal of Accounting Education, Vol. 17, No. 2/3, Spring/Summer 1999 (pp. 255-266).

2. Gagnon, Roger J. and Ravi Krovi. "Internet Use: Are Instructors Up to Speed?” OR/MS Today, Vol. 27, No. 5, October 2000.

3. Jones, Steve and Camille Johnson-Yale. "Professors online: The Internet's impact on college faculty," First Monday, volume 10, number 9 (September 2005).

4. Poindexter, Sandra and Tawni Hunt Ferrarini. “A Five Year Sudy on Faculty Adoption of Internet Integration: Uses, Motivators, and Hindrances - What do they mean?” EDCAUSE 2004 Annual Conference.

5. Roxas, Maria L. and Lucia E. Peek. “Accounting programs' home pages: what's happening. (evaluating content and design of business school accounting department web sites)," Journal of Education for Business, Vol. 77, No. 4 Mar-Apr 2002 (pp. 207-13). 
6. St. Clair, Sean and Nelson C. Baker. "Faculty use and impressions of courseware management tools: A national survey," Journal of Engineering Education, Vol. 92, No. 2, April 2003 (pp. 113-121).

7. Woods, Robert, Jason Baker and Dave Hopper. "Hybrid structures: Faculty use and perception of webbased courseware as a supplement to face-to-face instruction," The Internet and Higher Education, Vol. 7, Issue 4, 2004 (pp. 281-297).

\section{NOTES}

